\title{
Cardiac magnetic resonance dual bolus myocardial perfusion quantification superior to the single bolus analysis method
}

\author{
Kaatje Goetschalckx ${ }^{1,2^{*}}$, Piet Claus ${ }^{2}$, Jan Bogaert ${ }^{3}$, Attila Tóth $^{4}$, Béla Merkely ${ }^{4}$, Stefan Janssens ${ }^{1,2}$, \\ Frank E Rademakers ${ }^{2}$
}

From 18th Annual SCMR Scientific Sessions

Nice, France. 4-7 February 2015

\section{Background}

Quantitative assessment of myocardial blood flow (MBF) with first-pass perfusion cardiac magnetic resonance (CMR) is subject to disparity in methodology. The aim of this study was to compare single (SB) and dual bolus (DB) analysis methods in a large patient population with recently revascularized myocardial infarction.

\section{Methods}

In this substudy of the NOMI-trial (ClinicalTrials.gov identifier: NCT01398384), CMR rest and adenosine stress perfusion were analyzed in 119 patients at 4 months after acute myocardial infarction with TIMI 2-3 flow after primary PCI. A balanced turbo gradient echo sequence with non-shared prepulse was used in 1.5 tesla MR scanner (Achieva, Philips Medical Systems). MBF was quantified using Fermi deconvolution with SB (0.05 $\mathrm{mmol} / \mathrm{kg}$ ) and DB (equal volumes of $0.0027 \mathrm{mmol} / \mathrm{kg}$ followed by $0.05 \mathrm{mmol} / \mathrm{kg}$ of contrast agent) in $6 \mathrm{seg}$ ments of basal and midventricular short axis perfusion slices. Because of the increased movement and time consuming nature of the analysis, apical slices were excluded. Segments were grouped according to the presence of no (late gadolinium enhancement $\mathrm{LGE}=0$ ), little $(\mathrm{LGE}<50 \%)$ or more then $50 \%$ of infarct scar $(\mathrm{LGE} \geq 50 \%)$

Table 1

\begin{tabular}{|c|c|c|c|c|c|c|}
\hline 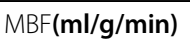 & $\mathrm{LGE}=0$ & LGE $<50$ & $L G E \geq 50$ & $\mathrm{p}$ & $p$ & $p$ \\
\hline mean \pm SD (n) & 1 & 2 & 3 & $1-2$ & $2-3$ & $1-3$ \\
\hline \multicolumn{7}{|l|}{ REST } \\
\hline SB & $1.36 \pm 0.58(741)$ & $1.22 \pm 0.47(199)$ & $1.12 \pm 0.58$ & $<0.05$ & $<0.05$ & $<0.05$ \\
\hline DB & $0.43 \pm 0.21(719)$ & $0.37 \pm 0.18(191)$ & $0.35 \pm 0.18(196)$ & $<0.05$ & 0.09 & $<0.05$ \\
\hline \multicolumn{7}{|l|}{ STRESS } \\
\hline SB & $3.22 \pm 1.22(683)$ & $2.68 \pm 1.16(190)$ & $2.21 \pm 1.14(205)$ & $<0.05$ & $<0.05$ & $<0.05$ \\
\hline $\mathrm{DB}$ & $1.33 \pm 0.57(688)$ & $1.08 \pm 0.54(192)$ & $0.88 \pm 0.47(204)$ & $<0.05$ & $<0.05$ & $<0.05$ \\
\hline \multicolumn{7}{|l|}{ MPR } \\
\hline SB & $2.69 \pm 1.45(624)$ & $2.39 \pm 1.29(176)$ & $2.30 \pm 1.57(177)$ & $<0.05$ & ns & $<0.05$ \\
\hline $\mathrm{DB}$ & $3.65 \pm 1.93(609)$ & $3.36 \pm 1.99(173)$ & $2.98 \pm 1.67(175)$ & $<0.05$ & ns & $<0.05$ \\
\hline
\end{tabular}

$\mathrm{MPR}=$ myocardial perfusion reserve $=\mathrm{MBF}$ stress $/ \mathrm{MBF}$ rest 


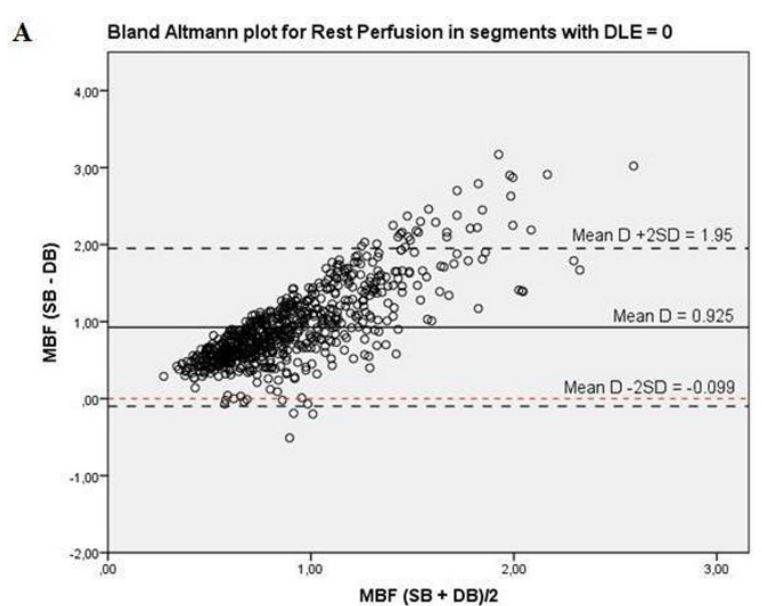

B Bland Altmann plot for Rest Perfusion in segments with DLE $<50 \%$

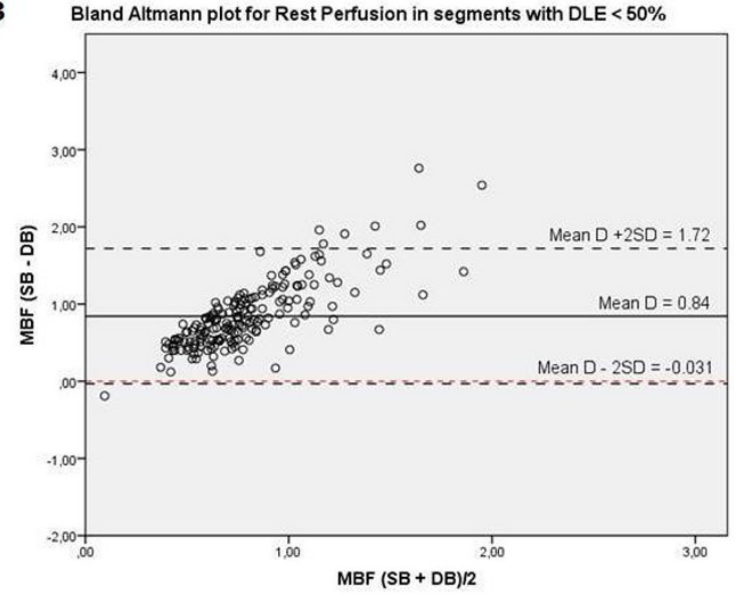

C Bland Altmann plot for Rest Perfusion in segments with DLE $\geq 50 \%$

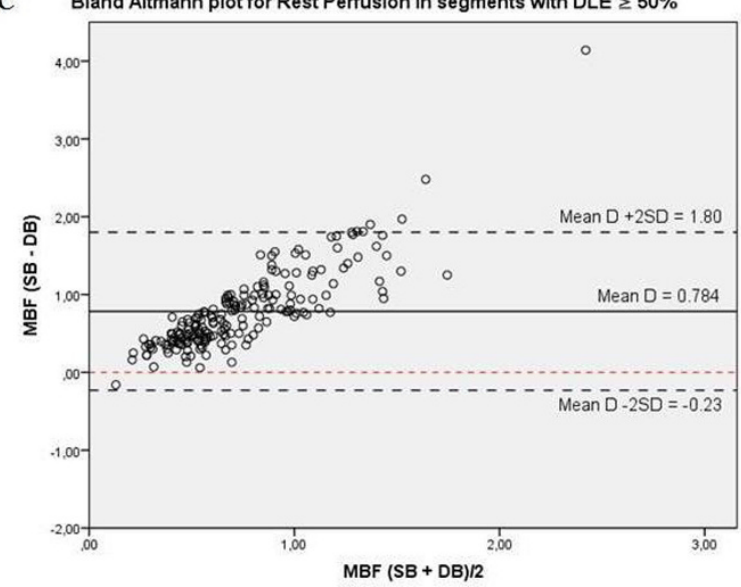

Figure 1

on corresponding LGE-images. Myocardial perfusion reserve (MPR) was calculated by dividing stress by rest MBF. In a subset of 5 patients, perfusion analysis of the midventricular slice at rest and stress was repeated by the same (KG) and another observer (PC), both blinded to the first results, to obtain intra- and interobserver variability respectively, by calculating the coefficients of variation $(\mathrm{COV})$. 


\section{Results}

Two hundred thirthy eight slices with a total of 1428 segments were analyzed for rest and stress perfusion with both methods. MBF quantification is feasible in infarcted and non-infarcted segments with SB and DB, with at least $84 \%$ of segments being analyzable and a good correlation $(\mathrm{r}=0.81, \mathrm{p}<0.01)$ between methods. MBF decreases significantly in segments with increasing infarct size, both at rest and during stress. MPR also decreases significantly with increasing infarct size. (cf. Table 1) MBF values with SB are high due to saturation effects even at a dose of $0.05 \mathrm{mmol} / \mathrm{kg}$. (cf. Figure 1).

Inter- and intra-observer variability of $\mathrm{DB}$ is smaller than for $\mathrm{SB}$, with an inter-observer $\mathrm{COV}$ of respectively 16 and $24 \%$ for rest perfusion, and 14 and $21 \%$ for stress perfusion, and an intra-observer COV of respectively 16 and $19 \%$ for rest perfusion, and 20 and $21 \%$ for stress perfusion.

\section{Conclusions}

Quantification of rest and stress perfusion with DB is superior to SB, because the SB method is more subject to saturation effects and analysis reproducibility is better for DB.

\section{Funding}

No disclosures.

\section{Authors' details}

${ }^{1}$ Division of Cardiovascular Diseases, University Hospitals Leuven, Leuven, Belgium. ${ }^{2}$ Department of Cardiovascular Sciences, University Hospitals Leuven, KU Leuven, Leuven, Belgium. ${ }^{3}$ Department of Radiology, University Hospitals Leuven, Leuven, Belgium. ${ }^{4}$ Heart and Vascular Center, Semmelweis University, Budapest, Hungary.

Published: 3 February 2015

doi:10.1186/1532-429X-17-S1-P58

Cite this article as: Goetschalckx et al:: Cardiac magnetic resonance dual bolus myocardial perfusion quantification superior to the single bolus analysis method. Journal of Cardiovascular Magnetic Resonance 201517 (Suppl 1):P58.
Submit your next manuscript to BioMed Central and take full advantage of:

- Convenient online submission

- Thorough peer review

- No space constraints or color figure charges

- Immediate publication on acceptance

- Inclusion in PubMed, CAS, Scopus and Google Scholar

- Research which is freely available for redistribution

Submit your manuscript at www.biomedcentral.com/submit 